\title{
Políticas de preservação digital para documentos arquivísticos
}

Henrique Machado dos Santos

Bacharel em Arquivologia pela Universidade Federal de Santa Maria (UFSM).Arquivista do escritório Martini, Medeiros \& Tonetto: advogados associados.Integrante dos grupos de pesquisa CNPq-UFSM: Gestão Eletrônica de Documentos Arquivísticos (GED/A) e Patrimônio Documental Arquivístico (PDA)

Daniel Flores

Doutor em Metodologías y Líneas de Investigación en Biblioteconomía y Documentación pela Universidad de Salamanca (USal). Professor Adjunto do Departamento de Documentação e do Mestrado em Patrimônio Cultural da Universidade Federal de Santa Maria (UFSM). Líder dos grupos de pesquisa CNPqUFSM: Gestão Eletrônica de Documentos Arquivísticos (GED/A) e Patrimônio Documental Arquivístico (PDA)

http://dx.doi.org/10.1590/1981-5344/2542

Este artigo realiza uma reflexão abrangente sobre as políticas de preservação digital para documentos arquivísticos, com ênfase na manutenção da fidedignidade e na garantia de acesso em longo prazo. Desta forma, são perpassados os seguintes aspectos: a evolução das tecnologias da informação; o advento do documento digital; o uso de padrões abertos; o uso de metadados; os custos relacionados; a segurança; e o planejamento da preservação em longo prazo. A metodologia consiste no levantamento bibliográfico-documental, composto por materiais previamente publicados, dentre eles: livros, teses, dissertações, textos em sites da Internet e artigos em periódicos científicos indexados no Google Scholar. Constitui uma revisão de literatura, que aborda principalmente trabalhos contemporâneos, publicados nos últimos quinze anos, período em que as discussões sobre a preservação digital se acentuaram. Desta forma, os dados coletados são processados através da análise qualitativa, e posteriormente, estruturados em seções temáticas, que apontam os principais entraves teóricos. 
Palavras-chave: Documentos arquivísticos digitais. Preservação digital. Políticas de preservação. Fidedignidade. Documentos digitais.

\section{Digital preservation policies for archival documents}

This article presents a comprehensive reflection on digital preservation policies for archival documents, with emphasis on maintaining the reliability and guaranteed access in long-term. Thus, the following aspects are covered: the development of information technologies; the advent of digital document; the use of open standards; the use of metadata; related costs; the security; and planning of preservation in long-term. The methodology consists of search bibliographic and documentary, composed of previously published material, including: books, theses, dissertations, texts on Internet sites and articles in scientific journals indexed in Google Scholar. It is a literature review, which mainly addresses contemporary works published in the last fifteen years, period when discussions on digital preservation have widened. Thus, the collected data is processed by qualitative analysis and subsequently structured in thematic sections that link the main theoretical barriers.

Keywords: Digital archival documents. Digital preservation. Digital preservation policies. Reliability. Digital documents.

Recebido em13.09.2014 Aceito em 16.11.2015

\section{Introdução}

A sociedade contemporânea está vivendo uma nova etapa de sua evolução, nesta fase, a presença da informação registrada em dígitos binários tem um significado muito maior do que se pode a priori imaginar (LOPES, 1997). A crescente demanda por tecnologias da informação teve impacto nos mais diversos setores da sociedade, assim, há um grande fluxo de dados circulando por meio de computadores.

Atualmente, as ferramentas de tecnologias da informação ocupam um lugar de destaque na sociedade, e são consideradas indispensáveis ao progresso científico, tecnológico e econômico. Não há como imaginar a sociedade atual sem as tecnologias, em especial as de informação e 
comunicação. Desta forma, a produção de documentos mediada por computadores vem se tornando um fato indissociável, em virtude da praticidade de criação e disseminação de conteúdos.

As organizações públicas e privadas, bem como os cidadãos, estão produzindo documentos em formato digital com certa diversidade (BRASIL. Conselho Nacional de Arquivos, 2004). Neste sentido, destaca-se que o funcionamento das organizações depende cada vez mais de informações, que estão em maior número, diversidade e complexidade quando comparadas ao passado (LOPES, 1996). Assim as instituições responsáveis pela memória, como arquivos, bibliotecas e centros de documentação, além preservarem documentos em suportes tradicionais, agora precisam preservar os documentos digitais (HEDSTROM, 1998).

Neste contexto, diversas ferramentas de tecnologias da informação foram introduzidas no campo pragmático da arquivística, fato que vem estimulando a produção de documentos digitais. Pode-se dizer que tamanha demanda é consequência da assombrosa facilidade de se criar, editar, excluir, difundir e acessar as informações em meio digital. E como resultados, destaca-se a preferência dos usuários por documentos digitais, em virtude das facilidades de disseminação e acesso.

Observa-se que a demanda por documentos criados em meio digital e as incertezas quanto a sua preservação estão ameaçando a capacidade de se continuar utilizando os arquivos como fontes confiáveis (THOMAZ, 2005). Isto porque, o ritmo acelerado da evolução tecnológica criou um grande paradoxo: há uma grande facilidade para criar documentos digitais, entretanto, os métodos de preservação ainda são escassos e a maioria ainda não teve sua eficácia comprovada em longo prazo. Da mesma forma, a fragilidade implícita vem ameaçando a garantia de integridade e autenticidade. Assim, há um grande volume de documentos digitais, sejam eles, de valor administrativo, histórico ou informativo, que estão correndo o risco de perda.

Considerando as questões apresentadas, tem-se por objetivo realizar uma reflexão abrangente sobre a preservação de documentos arquivísticos digitais, com ênfase nas políticas de preservação. Para isto, são perpassados aspectos como: a evolução das tecnologias da informação; o advento do documento digital; o uso de padrões abertos; o uso de metadados; os custos relacionados; a segurança e o planejamento da preservação em longo prazo.

A metodologia utilizada consiste no levantamento bibliográficodocumental, composto por materiais previamente publicados, dentre eles, livros, teses, dissertações, textos em sites da Internet e artigos em periódicos científicos indexados no Google Scholar. Caracteriza-se como uma revisão de literatura, que aborda principalmente, os trabalhos publicados nos últimos quinze anos, período no qual as discussões sobre a preservação digital foram acentuadas. Desta forma, os dados coletados são analisados através do método qualitativo e estruturados em seções temáticas, apontando assim, os seus principais entraves teóricos no âmbito da arquivística (GIL, 2010; LUNA, 1997; SILVA; MENEZES, 2005). 
A justificativa deste estudo fundamenta-se no cenário de acelerada evolução tecnológica aliada à ausência de práticas de preservação em longo prazo, o que pode acarretar graves perdas para a memória das sociedades contemporâneas. Dentre suas limitações, por se tratar de uma reflexão abrangente do problema, parte-se da análise do geral para o específico, procedimento no qual, detalhes mais precisos não são contemplados.

\section{0 impacto das tecnologias da informação}

O avanço da tecnologia da informação expandiu o uso de softwares para a sociedade, e desta forma, há maior disponibilidade, heterogeneidade e volume de dados e informações armazenados em sistemas computacionais (DE SORDI, 2008). Atualmente as atividades de pesquisa estão dependendo cada vez mais da informação registrada em bits, o que reforça o estabelecimento de modelos para a preservação e curadoria dos dados digitais (SAYÃO, 2010a; SAYÃO; SALES, 2012). Observa-se que as tecnologias da informação vêm se expandindo para diversos segmentos, e o seu impacto é expresso por sua dependência.

Conforme os dados são estruturados em informações, e então registrados, surgem os documentos digitais, concebidos como dados e informações registrados em um suporte. Assim, devido a sua facilidade de produção, ocorre a demanda por documentos digitais, impulsionada pelo volume informacional armazenado nos sistemas computacionais, os quais passaram a ser registrados em diferentes suportes de mídia, em diferentes formatos de arquivo, e criados por softwares de diferentes versões.

Tamanha demanda por formatos digitais pode ser observada como um fator condicionado da evolução da tecnologia. Observa-se que o documento evoluiu com relação a sua forma e suporte, sendo representado sobre a natureza de imagem, áudio, vídeo, bases de dados, que podem ser armazenados em suportes de mídia óptica e magnética. Além disso, o documento e o respetivo suporte físico são perfeitamente separáveis, desta forma, a informação que era fixada em suporte convencional passa a ser armazenada em suporte eletrônico, deixando de ter uma relação indissociável. Assim, a facilidade de recopiar documentos registrados em diferentes suportes físicos, acrescenta maior flexibilidade aos documentos digitais (BODÊ, 2007).

A ruptura mais notável entre as caraterísticas de representação dos documentos digitais e convencionais, paralelamente, dissemina a ideia de documento digital como um elemento virtual, imaterial. Embora seja fruto de uma primorosa evolução das tecnológicas de informação, o documento ao ser representado em digital, não deve ser abordado como um elemento "virtuoso" que não ocupa espaço. Este pensamento é equivocado, pois os bits que compõe o documento precisam ser logicamente ordenados por meio de uma linguagem, para serem registrados fisicamente em um suporte eletrônico, o qual é um objeto material. Neste sentido, destaca-se 
a grande mudança: não é possível ler os documentos digitais de maneira direta, o que faz do computador, um importante intermediário para interpretar e representar estes registros.

Considerando o pensamento de Bodê (2007), de que o documento é condicionado à tecnologia, pode-se encontrar facilmente uma convergência com as ideias de Marcondes (2010), ao comentar que os documentos foram modificados gradativamente, e são continuamente aperfeiçoados sob algum aspecto relevante.

Os documentos, então condicionados à tecnologia, perpassaram diversos suportes em sua constante evolução. Isto abrange desde os suportes mais primitivos como as tabuinhas de barro, papiros, pergaminhos, códices, até os contemporâneos, que são os documentos impressos e principalmente os documentos digitais. Há mudanças notáveis, porém, alguns elementos permanecem sendo os mesmos. De maneira geral, os documentos são unidades de registro e transferência de mensagens. A ideia de imaterialidade dos documentos digitais se caracteriza como um fato decorrente da recente evolução das tecnologias, a qual se estima que seja superada com o próprio desenvolvimento das tecnologias. Além disso, discussões referentes à imaterialidade dos documentos digitais não trazem um sentido prático, pois sua aplicação é limitada ao campo teórico (MARCONDES, 2010).

A evolução das tecnologias da informação proporcionou diversas mudanças tanto na teoria quanto na prática. Paralelamente a estas, há uma pseudo-ruptura, ou seja, uma sensação de que documentos digitais são completamente distintos dos tradicionais, o que não é verdade, pois o que ocorreu foi uma transformação decorrente de uma evolução natural das tecnologias.

Em meio a estas mudanças inicia-se um longo processo de revisão e reformulação dos princípios arquivísticos, sejam eles de ordem epistemológica ou pragmática. Logo, pode-se considerar as tecnologias da informação como um ponto de reformulação, constituindo um novo marco na evolução da Arquivologia (FONSECA, 2005; RONDINELLI, 2005).

\section{Documento arquivístico digital: demanda e vulnerabilidades implícitas}

O documento arquivístico digital surgiu em virtude da evolução das tecnologias da informação, mais precisamente com a entrada de suas ferramentas na Arquivologia. Desta forma, a informação orgânica começou a ser registrada por meio de computadores, tornando necessária a redefinição de conceitos, bem como a criação de teorias para contemplar os documentos arquivísticos em meio digital.

O documento digital se difere dos padrões tradicionais conhecidos, há mudanças que vão além dos meios de registro e armazenamento, dentre elas, a leitura direta e a relação indissociável do suporte. A informação é codificada em bits, e desta forma, a leitura do documento 
ocorre por intermédio de softwares, igualmente codificados em bits e acessíveis somente por meio de computadores (RONDINELLI, 2013).

A evolução da tecnologia em ritmo acelerado provocou o fascínio da sociedade, e desta forma, diversos setores incorporaram as ferramentas de tecnologias da informação a fim de executar suas atividades. Observase que a rápida expansão para o meio digital ocorreu sem mensurar os possíveis impactos desencadeados pela tecnologia, colocando parte significativa da memória social em risco. Logo, grandes volumes de documentos digitais podem ser perdidos devido às falhas de planejamento e a insuficiência de conhecimentos sobre os efeitos da obsolescência tecnológica.

Os computadores facilitaram o gerenciamento e o acesso das informações, desta forma, o advento do documento arquivístico digital proporcionou uma série de vantagens como a economia de espaço físico e o acesso à distância. Entretanto, os documentos digitais possuem uma série de complexidades e especificidades decorrentes de sua natureza digital, e tanto a obsolescência tecnológica, quanto o uso inadequado dos computadores, pode levar a perca de registros relevantes, deixando assim, imensas lacunas nos acervos arquivísticos. Da mesma forma, a ausência de procedimentos de segurança e preservação ameaçam a autenticidade e a confiabilidade dos documentos digitais, pois estes registros são facilmente alterados, duplicados, convertidos, e até mesmo falsificados sem deixar vestígios aparentes (BRASIL. Conselho Nacional de Arquivos, 2014; 2011; 2012; CORRÊA, 2010; FERREIRA， 2006; INNARELLI, 2006; INTERPARES, 2007a; PAES, 2004; ROCHA; SILVA, 2007).

Pode-se dizer que o documento arquivístico digital está inserido em um cenário de incertezas, pois as ferramentas de tecnologias da informação facilitam a sua produção, entretanto, a sua preservação em longo prazo ainda é incerta e abstrata. Neste contexto, é preciso preservar os documentos produzidos no passado, produzidos na atualidade, e aqueles que serão produzidos no futuro, por meio de tecnologias ainda não conhecidas. Tais fatos agravam o problema, pois os documentos digitais estão se tornando cada vez mais complexos. Destacase que estes registros estão condicionados a um cenário no qual a tecnologia não vai parar de avançar, proporcionando novos softwares, novas versões, com mais recursos, e gerando maior diversidade de formatos de arquivo, o que agrava a complexidade e a especificidade dos documentos arquivísticos digitais.

De maneira geral, o documento digital é produto de uma recente evolução das tecnologias da informação e isto implica em desconhecer algumas de suas conveniências, assim como parte de suas limitações. No entanto, documentos arquivísticos digitais estão sendo produzidos, e parte destes registros precisa ser preservada em longo prazo, em um contexto onde a capacidade de preservação é menor do que a de produzir, logo não há nenhuma garantia de longevidade. 
Ressalta-se que apesar da carência de métodos de preservação em longo prazo, muitas coleções digitais as quais contém documentos relevantes estão sendo construídas fora do espaço de arquivos e bibliotecas. Este fato pode ser observado em diferentes organizações que produzem documentos e os publicam diretamente na Internet. Desta forma, a partir do aumento da produção de documentos digitais tem se questionado a importância e a capacidade de garantir a preservação em longo prazo de maneira confiável (MÁRDERO ARELLANO, 2008). Desta forma, a intervenção arquivística se faz necessária antes mesmo da criação dos documentos digitais, pois estes não sobrevivem sem tratamento diferentemente dos seus equivalentes impressos (FONSECA, 2005; SAYÃO; SALES, 2012).

Com a exceção de bibliotecas, arquivos e centros de documentação e informação, pode-se dizer que as organizações de modo geral não estão habituadas a preservar documentos, sejam eles digitais ou analógicos. Neste contexto, os documentos digitais correm um sério risco com relação à preservação de longo prazo. Não há nenhum exagero em se afirmar que instituições tradicionalmente responsáveis pela preservação estão com dificuldades para se adaptar a realidade digital.

No contexto atual, há conteúdos de valor relevante sendo produzidos diariamente, tanto dentro, quanto fora das instituições encarregadas pela preservação da memória. De alguma forma, estes registros precisam ser preservados para atender aos respectivos fins que motivaram a sua criação, o que reforça a necessidade de um maior aprofundamento teórico-prático na preservação digital.

\section{Preservação digital}

A preservação digital objetiva garantir o acesso contínuo em longo prazo a informação digital íntegra e autêntica, de modo que suas funcionalidades possam ser reproduzidas corretamente por uma tecnologia do futuro, que é diferente daquela que lhe originou no passado (BRASIL. Conselho Nacional de Arquivos, 2014; FERREIRA, 2006; THOMAZ; SOARES, 2004) Além disso, também é preciso manter, paralelamente, uma descrição do documento digital a ser preservado (CONWAY, 2001). Para tal, não apenas copiar o documento digital é preciso manter sua diplomática e suas propriedades significativas, sendo abordada de forma interdisciplinar e institucional (INNARELLI, 2007; 2012).

A preservação digital é composta por procedimentos de manutenção, que podem ser denominados estruturais e por procedimentos de preservação dos componentes, os quais podem ser denominados como operacionais. Os procedimentos estruturais se referem aos estágios iniciais, definindo questões como a infraestrutura, normas, escolha de padrões, financiamentos e definição de metadados. Já os procedimentos operacionais se referem a atividades que objetivam a preservação física, lógica e intelectual dos documentos digitais através 
ações como a migração, a emulação e o encapsulamento (INTERPARES, 2007a; MÁRDERO ARELLANO, 2004; 2008; THOMAZ, 2004; THOMAZ; SOARES, 2004; WEBB, 2003). Podem-se resumir os procedimentos estruturais como sendo as políticas e os operacionais como sendo as atividades aplicadas à manutenção dos documentos digitais. Assim, para o atingimento do objetivo deste estudo, delimita-se a discussão para os procedimentos estruturais, com ênfase nos aspectos relevantes para uma política de preservação de longo prazo.

\section{Análise das estratégias estruturais}

A preservação digital requer o uso de infraestrutura física e tecnológica adequada, políticas institucionais bem definidas que requeiram a conformidade com normas e a presença de uma equipe de profissionais qualificados para realizar as atividades. Esta sincronia deverá ser considerada desde os estágios iniciais do processo.

Uma política de preservação digital requer a identificação dos riscos, para assim, poder evitá-los ou minimizá-los. Deve contemplar a gestão de segurança de acordo com padrões amplamente aceitos. Além disso, é preciso estabelecer um plano de ação que garanta tanto o acesso, quanto a acessibilidade, ou seja, as condições de acesso em longo prazo (CASANOVAS, 2008). Assim, discutem-se questões como o uso de padrões de software, formatos e metadados; os custos envolvidos no desenvolvimento da infraestrutura técnica e tecnológica; a segurança; a definição de normas; e o planejamento.

\subsection{Uso de padrões}

Inicialmente o uso padrões vem se constituindo como uma importante iniciativa para os acervos digitais. Através destes é possível reduzir a diversidade de formatos de arquivo, além de reduzir os riscos de obsolescência tecnológica.

Há dois tipos de padrões: de facto e de jure. Os padrões de jure são aqueles que foram aprovados e regulamentados por um órgão competente como a International Organization for Standartization (ISO) e desta forma, é possível ter acesso as suas especificidades as quais foram documentadas. Já os padrões de fato não aqueles que foram aprovados por órgão regulamentadores, porém eles são amplamente utilizados (INTERPARES, 2007b).

A adoção de padrões de facto ou de jure, com ênfase nos formatos abertos, proporciona maior estabilidade e suporte técnico em longo prazo. Estes formatos têm um risco de obsolescência menor, e desta forma, é possível reduzir ou minimizar a frequência da execução de estratégias, como por exemplo, a migração (THOMAZ, 2004). Logo, o planejamento e a implementação de padrões para formatos de arquivo é um dos meios de assegurar a preservação e o acesso aos documentos digitais em longo prazo, além de auxiliar na presunção de autenticidade (INNARELLI, 2007; 
2012). Caso haja um consenso do uso de um determinado padrão, este poderá se tornar uma norma, e até mesmo, um requisito para a entrada de novos documentos no acervo (HEDSTROM, 2001). Observa-se que o uso de tecnologias mais estáveis proporciona maior segurança para o acervo, reduzindo as atividades de manutenção, bem como os seus custos implícitos.

Neste sentido, o Arquivo da Web Portuguesa (AWP) apresenta uma lista contendo diversos formatos de arquivo, que são classificados conforme uma escala de recomendação (alta, média e baixa). Um formato adequado para preservação deve ser livre de qualquer restrição de uso; ter código aberto e documentado; ser amplamente utilizado; multiplataforma; preferencialmente sem compressões ou de compressão sem perdas; e configurar uma norma emitida por um organismo oficial. Já um formato não recomendado para preservação é aquele que possui direito proprietário, tem código fechado; é pouco difundido; é criado e interpretado por poucas plataformas de software de código fechado; possuí compressão com perdas; ou é composto por elementos internos (AWP, 2007). Embora estas recomendações visem à preservação do conteúdo de sites, boa parte de suas recomendações podem ser logicamente adotadas para preservar documentos institucionais.

De maneira geral, a definição de padrões para a preservação de documentos digitais é uma iniciativa muito relevante, entretanto, as tecnologias da informação seguem evoluindo de forma dinâmica, e com isto, a definição de padrões está longe de ser uma atividade palpável. Os padrões de hoje podem mudar em virtude da evolução tecnológica, e por isto, ainda não oferecem uma solução para as atividades de preservação digital (ROTHENBERG, 1999). Os padrões devem ser considerados como uma definição relevante para o acervo, mas nunca como uma solução para os problemas de obsolescência.

\subsection{Metadados}

Metadados são dados que descrevem outros dados, formando uma estrutura abstrata denominada esquema ou conjunto de metadados. Esta estrutura é criada para fins específicos sendo necessária para identificar, representar, interoperar e gerir o funcionamento e a utilização dos conteúdos de um sistema de informação (DE SORDI, 2008; SAYÃO, 2010b).

Os metadados são componentes dos documentos arquivísticos digitais que descrevem suas propriedades. Estes componentes são necessários à manutenção e comprovação da integridade, autenticidade e fidedignidade dos documentos, constituindo-se como instrumentos de análise diplomática dos documentos. Logo é fundamental que todas as informações essenciais estejam registradas corretamente (INTERPARES, 2007b; RONDINELLI, 2005). Assim, os metadados fornecerão uma descrição ampla do documento digital, considerada fundamental para comprovação de sua fidedignidade. 
Os padrões metadados são importantes para informar o contexto tecnológico dos documentos digitais, para que os futuros usuários compreendam o ambiente em que foi criado, bem como o seu histórico de manutenção (INNARELLI, 2012; MÁRDERO ARELLANO, 2004). Através destes padrões é possível registrar a cadeia de custódia dos documentos digitais e de seus respectivos componentes. Além disso, os metadados podem identificar os documentos de forma única, tanto interna, quanto externamente, em relação ao acervo ao qual pertencem. Logo, os metadados de preservação tornam-se componentes-chave para grande parte das estratégias de preservação digital, pois tem a função de documentar todas as ações proferidas sobre os documentos (SARAMAGO, 2004; THOMAZ, 2004; THOMAZ; SANTOS, 2003).

Neste contexto, os metadados atuam fornecendo informação de apoio à preservação em longo prazo, criando assim, um histórico das transformações ocorridas. Ressalta-se que a finalidade é garantir a reconstrução da integridade e da autenticidade dos documentos (SARAMAGO, 2004). De maneira geral, os metadados de preservação são fundamentais para a garantia de acesso fidedigno em longo prazo, fornecendo assim, um histórico o qual irá auxiliar na interpretação dos documentos digitais.

\subsection{Custos}

A preocupação com a preservação dos documentos digitais é o princípio da elaboração de uma política institucional, o qual deverá considerar os recursos necessários para garantir a realização de todas as etapas do trabalho. Sem esta premissa inicial não há razão para se investir em um trabalho de longo prazo (SANTOS; FLORES, 2015a). Inicialmente é preciso identificar o propósito de preservar a viabilidade do mesmo, considerando assim, as possíveis intempéries.

A preservação digital é uma atividade complexa que envolve diversas variáveis, dentre elas, podem-se destacar, a necessidade de investimentos em pesquisa, infraestrutura técnica e tecnológica. Desta forma, pode-se considerar inicialmente que estabelecer parcerias entre instituições com objetivo de preservar a memória como sendo a solução mais viável (BRASIL. Conselho Nacional de Arquivos, 2014). A união de esforços em prol da preservação irá potencializar as atividades, agregando para as instituições envolvidas, mais conhecimentos sobre as vantagens e desvantagens dos diferentes métodos de preservação.

Destaca-se que a identificação de possíveis ameaças durante a elaboração das políticas de preservação permite evitar ou mesmo minimizar seus efeitos, contribuindo consideravelmente para uma gestão eficiente dos recursos financeiros da instituição (BELARMINO; ARAúJO, 2014). O constante monitoramento das tendências tecnológicas irá auxiliar na identificação de softwares, formatos e sistemas potencialmente obsoletos, desta forma, é possível buscar alternativas a fim de minimizar os seus impactos. 
É preciso compreender que cada procedimento de preservação implica em um determinado planejamento que requer diferentes custos. Logo, a preservação digital necessita de recursos financeiros contínuos, disponíveis no longo prazo (MÁRDERO ARELLANO, 2008), fato que reforça a necessidade de se realizar parcerias com outras instituições.

A preservação digital de longo prazo envolve custos elevados, mas tal atividade é fundamental para garantir a salvaguarda do patrimônio e a memória, bem como para auxiliar nos processos de tomada de decisão (INTERPARES, 2007b). Desta forma, destaca-se a importância de promover a sustentabilidade econômica, ou seja, administrar os recursos necessários para alcançar os objetivos da preservação digital no longo prazo (MÁRDERO ARELLANO, 2008). Pode-se dizer que o sucesso da preservação requer um investimento.

\subsection{Segurança}

A segurança é um ativo essencial para que as instituições possam salvaguardar seus acervos. No caso da informação em meio digital há necessidade de tecnologias que garantam a sua integridade, autenticidade e confidencialidade (DORNELES; CORRÊA, 2013). Pode-se considerar a segurança como o primeiro passo para se iniciar as atividades de preservação em longo prazo.

As medidas de segurança incluem tanto a restrição física os computadores, quanto o acesso aos respetivos materiais digitais. Há diversas formas para restringir o acesso aos documentos digitais, dentre elas, o uso de senhas e autenticação biométrica para acessar o sistema. Além disso, o sistema utilizado deve manter uma trilha de auditoria para identificar o acesso e as alterações sobre os materiais, e da mesma forma, controlar a administração do sistema e os privilégios de acesso (INTERPARES 2007b). Ressalta-se ainda a necessidade de se verificar quem proferiu as alterações, sendo possível restaurar os valores anteriores.

Outra questão muito pertinente são as rotinas de backup, as quais são consideradas essenciais na preservação digital, pois garantem a restauração dos dados de forma íntegra e confiável (INNARELLI, 2012). Tendo em vista a relação entre o seu custo e seus benefícios, o backup é uma alternativa econômica e simples (CASANOVAS, 2008). No entanto, para garantir sua eficácia é preciso manter os metadados vinculados aos documentos digitais, os quais são tão importantes quanto o próprio documento digital (SOMASUNDARAM; SHRIVASTAVA, 2011). Neste sentido, ressalta-se que é fundamental que o backup preserve os metadados do documento, caso contrário sua presunção de autenticidade será profundamente abalada. Além disso, deve-se garantir a capacidade de se restaurar versões anteriores tanto dos documentos, quanto dos sistemas de gestão e preservação. 


\subsection{Planejamento}

O documento digital é consequência de uma evolução muito recente, e por isto, não há práticas comprovadas que garantam a sua preservação em longo prazo, no entanto, as atividades de pesquisa e implementação de estratégias tornam-se fundamentais. Neste sentido, o planejamento da preservação digital deve considerar a dinâmica do mercado, identificando assim, questões como as tendências tecnológicas e suas vulnerabilidades implícitas (SANTOS; FLORES, 2015a).

Ao se trabalhar com preservação digital, a figura do gestor torna-se essencial. Cabe a ele realizar atividades como o planejamento, a delegação de tarefas e os métodos de trabalho. Assim, objetiva-se agregar maior flexibilidade e confiança na equipe (BOERES; CUNHA, 2012). Neste sentido, o uso de padrões, os metadados, as questões de segurança e os custos envolvidos, devem ser considerados no planejamento da preservação, tendo em vista a necessidade de salvaguardar o patrimônio digital em longo prazo. Tais fatos realçam a necessidade do planejamento ser realizado antes de se implementar qualquer estratégia.

As atividades de preservação digital devem iniciar se possíveis, antes mesmo da criação do documento arquivístico. Logo, torna-se essencial considerar as potencialidades das tecnologias para manter a conformidade legal em relação às necessidades institucionais, o que vem a implicar diretamente na escolha dos sistemas informatizados de gestão, preservação e acesso (SANTOS, 2012). Além disso, é preciso considerar uma aproximação das práticas de preservação digital com as de gestão do conhecimento, fornecendo informações sobre os documentos digitais a fim de obter suporte no futuro. Tal convergência resulta em um ciclo de retroalimentação, pois a gestão do conhecimento tácito também precisa de práticas de preservação digital (FLORES; SANTOS, 2015). Questões como a gestão do conhecimento da preservação digital poderão fornecer uma base sólida sobre as práticas realizadas nos acervos, indicando as melhores alternativas, bem como possibilitando a troca de conhecimentos entre instituições parceiras. Uma base de conhecimento de preservação digital poderá compartilhar informações sobre formatos de arquivo, sistemas de gestão e estratégias de preservação, tornando-se assim, uma ferramenta fundamental à pesquisa e à prática.

O planejamento deve determinar claramente quais métodos de preservação serão adotados, definindo assim, as estratégias de curto, médio e longo prazo, e as respectivas ferramentas que as executam. Inicialmente, definem-se um conjunto de requisitos arquivísticos abrangendo forma fixa, conteúdo estável, variabilidade limitada e demais propriedades significativas do documento digital as quais se almejem preservar. Posteriormente, deve-se implementar ferramentas que realizarem a manutenção destes requisitos. Observa-se que as tecnologias devem ser adaptadas a fim de contemplar os requisitos arquivísticos, já 
estes nunca devem ser adaptados às funcionalidades das tecnologias (SANTOS; FLORES, 2015b; 2015c).

Em linhas gerais, a preservação de documentos digitais em longo prazo envolve diversas variáveis, dentre elas, o planejamento, as tecnologias e a viabilidade financeira. No entanto, essa complexidade vem desanimando as instituições que custodiam o patrimônio digital para as gerações futuras (SAYÃO, 2010a; 2010b). Desta forma, ressalta-se a necessidade de contextualizar a preservação digital como um problema não apenas tecnológico, mas também social, pois a memória das sociedades contemporâneas está correndo risco. Logo é preciso que as instituições responsáveis pela guarda da memória se adaptem rapidamente a realidade digital promovendo o avanço na pesquisa e a capacitação técnica dos envolvidos no processo.

\section{Políticas de preservação digital: em busca de uma definição}

A preservação de acervos arquivísticos requer o envolvimento da estrutura organizacional, no qual, as partes envolvidas devem auxiliar no processo como um todo. Inicialmente, devem-se definir questões basilares de forma que criem uma "cultura organizacional" que vislumbre a preservação de longo prazo. No entanto, é preciso ter claramente que documentos em suportes tradicionais e documentos digitais possuem a mesma relevância, não devendo assim, distingui-los com relação à prioridade de tratamento. A partir deste ponto, observam-se questões relacionadas à preservação dos documentos, no caso dos digitais, definem-se as estratégias a serem utilizadas.

Há distinções entre as estratégias estruturais e as operacionais que merecem destaque, tanto pela sua aplicabilidade, quanto pela ordem de implementação. As estruturais compreendem um conjunto de métodos para realizar a manutenção do ambiente de preservação. Pode-se dizer que elas são um conjunto de políticas organizacionais com a finalidade de manter o ambiente confiável, possibilitando assim, a implementação das estratégias operacionais. Já as estratégias operacionais, compreendem os métodos aplicados diretamente aos documentos para assegurar a sua preservação em longo prazo. Há diversas estratégias operacionais que podem ser implementadas em conjunto. Ressalta-se que haverá documentos digitais que não poderão ser submetidos a determinadas estratégias operacionais, o que reforça a necessidade de se utilizar tantas quantas forem necessárias. Durante a implementação das estratégias operacionais, deve-se manter a conformidade com o que foi definido nas estratégias estruturais, logo, elas se complementam. Assim, pode-se dizer que as estratégias estruturais são executadas, antes, durante e após qualquer estratégia operacional, o que vem a reforçar a relevância de aprofundar o seu estudo.

Após a análise das estratégias estruturais, é possível destacar alguns aspectos quanto aos itens a serem contemplados: uso de padrões; 
escolha dos metadados; custos relacionados às atividades; questões de segurança; e o planejamento da preservação de longo prazo.

Inicialmente, o uso de padrões deve ser considerado desde a produção dos documentos, desta forma minimizam-se os riscos de obsolescências, bem como as atividades operacionais em longo prazo, salvo os casos em que se ocorra a "mudança de padrão". Logicamente devem-se preferir os padrões abertos, de jure, e em segundo plano os padrões de facto. Observa-se que manter os documentos em formatos estáveis é fundamental para preservar seu acesso e sua fidedignidade, minimizando, por exemplo, possíveis percas motivadas por estratégias operacionais como a migração e os custos adicionais relacionados com a emulação.

Os metadados se configuram como importantes componentes digitais de um documento arquivístico, fornecendo informações relevantes em relação ao seu contexto tecnológico, as quais serão úteis para a sua preservação. Através da implementação de esquemas de metadados é possível ter um histórico das transformações dos documentos digitais, 0 que pode ser considerado um importante elemento para comprovar a sua fidedignidade. A informação em meio digital possui suas peculiaridades, e precisa ser "alterada" para ser preservada, isto quer dizer que os documentos precisam ser migrados ou convertidos, e isto implica em alterações na sequência original de bits. Pode-se dizer que não é possível preservar documentos digitais sem alterá-los, pois as tecnologias seguem evoluindo e assim, é preciso acompanhar a evolução dos softwares e dos formatos. Sendo assim, a ideia de autenticidade fica ameaçada por estas possíveis alterações, e desta forma, os metadados exercem a função de registrar quais são estas alterações, possibilitando assim, se as mesmas interferem ou não na presunção de autenticidade. Visto a necessidade de implementar esquemas de metadados ressalta-se que estes devem preferencialmente ser baseados em padrões abertos, da mesma forma que os formatos de arquivo, assim, tem-se mais liberdade na edição e possível redistribuição dos padrões de metadados utilizados no acervo.

Outro fator impactante na preservação são os custos envolvidos. Destaca-se que além da conscientização decorrente do risco de perca dos documentos, e do conhecimento de possíveis estratégias, é preciso dispor de recursos que custearão as atividades de manutenção em longo prazo. Isto implica em dispor de uma fonte de recursos garantida para que os projetos de preservação não sejam interrompidos no decorrer de sua execução, e consequentemente, se perca todo o trabalho realizado. Considera-se que a identificação das fontes de recursos deve ser a primeira etapa do plano de preservação, pois sem estes não faria sentido começar nenhum projeto. A escassez de recursos implicaria em limitações com relação à infraestrutura, o que dificulta manter os requisitos mínimos para a preservação.

Paralelamente às práticas de preservação digital, deve-se proporcionar um ambiente seguro para a guarda dos documentos, sendo possível controlar o acesso e as possíveis alterações proferidas sobre 
estes. A segurança pode ser considerada sobre dois pontos de vista: com relação a sua fidedignidade, e, com relação ao armazenamento seguro. No primeiro aspecto, a fidedignidade consiste na garantia de que o conteúdo não foi manipulado e que não há possibilidade de manipulá-lo sem que um mecanismo registre esta alteração. Neste sentido, as contas de usuário, as propriedades de acesso, as trilhas de auditoria e a capacidade de restaurar versões anteriores são fundamentais para caso ocorra alterações não autorizadas. Já o armazenamento seguro, requer rotinas de backup que compreendam tanto os documentos armazenados, quanto os sistemas de gestão, preservação e acesso. Caso seja necessário restaurar um backup, deve-se garantir que este irá recuperar todas as informações relacionadas aos documentos digitais. Ressalta-se que não basta copiar os dados, também é preciso manter sua relação orgânica e os seus metadados, não havendo assim, percas e nem acréscimos de dados.

A preservação de longo prazo requer a disponibilidade de recursos financeiros para então criar um ambiente seguro, no qual sejam implementados padrões de formatos, padrões de metadados, normas e estratégias operacionais. Mas paralelo a isto, há uma série de definições que devem ser consideradas, devendo-se ressaltar que o planejamento será fundamental para este trabalho de longo prazo. Inicialmente, devemse definir as ações, e, paralelamente, verificar a disponibilidade de recursos para estas. Observa-se que este processo vai se repetir para qualquer etapa da preservação, podendo assim, estabelecer a seguinte consideração: o planejamento de longo prazo é a principal atividade no processo de preservação digital, através dele é possível identificar a viabilidade de garantir o acesso fidedigno aos documentos arquivísticos digitais. Logo, o planejamento da preservação deve estar associado ao planejamento organizacional, desta forma, a organização como um todo se envolverá com o processo de preservação. As políticas de preservação digital precisam de prioridade organizacional, assim, será possível delegar os investimentos necessários para desenvolver a infraestrutura ideal, resultando em um ambiente confiável para a preservação de documentos digitais em longo prazo.

\section{Considerações finais}

Tendo em vista o objetivo proposto, este estudo realizou uma reflexão abrangente, fundamentada na revisão de literatura, a qual abordou as políticas de preservação para documentos arquivísticos digitais. Dentre os aspectos abordados, destacam-se: os avanços das tecnologias da informação; a demanda por documentos digitais; o uso de padrões abertos; o uso de esquemas metadados; os custos relacionados; a segurança do acervo; e o planejamento da preservação em longo prazo.

Conforme apresentado, os constantes avanços das tecnologias da informação transformaram os hábitos da sociedade contemporânea, gerando novas necessidades de consumo e sendo consideradas como 
elementos de competitividade. Fato é que as tecnologias da informação tornaram-se indispensáveis aos diversos segmentos da sociedade, desta forma, torna-se necessário se adaptar as suas transformações.

Decorrente dos avanços das tecnologias, o documento digital surge na Arquivologia e rapidamente ganha relevância em virtude do volume de dados que vem sendo produzidos pelas pessoas e principalmente pelas organizações modernas. Dentre estes, observa-se que há registros possuem um valor social, e se encontram em risco de perca em virtude da obsolescência tecnológica e ausência de práticas de preservação digital. Desta forma, a implementação de estratégias de preservação digital torna-se uma urgência, caso contrário, diversos registros serão perdidos e deixarão lacunas na memória social. Tais fatos reforçaram as motivações deste estudo, que se limita a abordar as estratégias de preservação estruturais, voltadas para as políticas de preservação.

A análise das estratégias estruturais explicitou fatores que devem ser pensados a priori de qualquer atividade. Desta forma, é preciso estabelecer: padrões de formatos; softwares; sistemas de gestão, preservação e acesso; esquemas de metadados; custos relacionados, segurança do acervo; e o planejamento das atividades.

A preservação digital necessita de práticas para salvaguardar os acervos, no entanto é preciso estabelecer um corpus teórico para as estratégias, sejam elas estruturais ou operacionais. Vive-se em um contexto no qual é preciso implementar soluções de preservação, porém estas soluções precisam de uma base teórica. Salienta-se que a prática sem auxílio da teoria é tão inútil quanto a teoria sem aplicação prática. Tal afirmação reforça que teorias devem vislumbrar a atividade prática, bem como a prática deve respeitar o que foi definido teoricamente a priori.

\section{Referências}

ARQUIVO DA WEB PORTUGUESA (AWP). Formatos adequados para preservação. Portugal: Lisboa, 2007. Disponível em: <http://sobre.arquivo.pt/colaboracoes/recomendacoes-para-autores-desitios-web/formatos-adequados-para-preservacao>. Acesso em: 4 nov. 2014.

BELARMINO, V. F.; ARAÚJO, W. J. Análise de vulnerabilidades computacionais em repositórios digitais. Biblios: Revista de Bibliotecología y Ciencias de la Información, Lima, n. 56, p. 1-18, abr/2014. Disponível em: <http://biblios.pitt.edu/ojs/index.php/biblios/article/view/169>. Acceso em: 2 set. 2015.

BODÊ, E. C. Preservação de acervos documentais eletrônicos. ARC: Revista Brasileira de Arqueometria, Restauração e Conservação. Olinda, v. 1 , n. 2, p. 32-35, 2007. Disponível em: <http://www.restaurabr.org/siterestaurabr/volumesarc/arc02pdf/07preser vacaodeacervos.pdf>. Acesso em: 15 dez. 2014. 
BOERES, S. A. de A.; CUNHA, M. B. da. Competências básicas para os gestores de preservação digital. Ciência da Informação, Brasília, v. 41 n. 1, p.103-113, jan./abr. 2012. Disponível em: $<$ http://revista.ibict.br/index.php/ciinf/article/view/2115>. Acesso em: 1 abr. 2015.

BRASIL. Conselho Nacional de Arquivos (CONARQ). Câmara Técnica de documentos eletrônicos. Carta para a Preservação do Patrimônio Arquivístico Digital. Rio de Janeiro: Arquivo Nacional, 2004. Disponível em:

<http://www.conarq.arquivonacional.gov.br/Media/publicacoes/cartaprese rvpatrimarqdigitalconarq2004.pdf >. Acesso em: 10 ago. 2014.

BRASIL. Conselho Nacional de Arquivos (CONARQ). Câmara Técnica de documentos eletrônicos. e-ARQ Brasil: Modelo de Requisitos para Sistemas Informatizados de Gestão Arquivística de Documentos. Rio de Janeiro: Arquivo Nacional, 2011. Disponível em: <http://www.conarq.arquivonacional.gov.br/media/publicacoes/earq/cona rq earqbrasil model requisitos 2009.pdf>. Acesso em: 05 ago. 2014.

BRASIL. Conselho Nacional de Arquivos (CONARQ). Câmara Técnica de documentos eletrônicos. Diretrizes para a presunção de autenticidade de documentos arquivísticos digitais. Rio de Janeiro: Arquivo Nacional, 2012. Disponível

em: < http://www.conarq.arquivonacional.gov.br/media/diretrizes presuncao autenticidade publicada.pdf>. Acesso em: 20 jun. 2014.

BRASIL. Conselho Nacional de Arquivos (CONARQ). Câmara Técnica de documentos eletrônicos. Diretrizes para a implementação de repositórios digitais confiáveis de documentos arquivísticos. Rio de Janeiro: Arquivo Nacional, 2014. Disponível em: <http://www.conarq.arquivonacional.gov.br/media/publicacoes/resol con arq 39 repositorios.pdf $>$. Acesso em: 13 ago. 2014.

CASANOVAS, I. Gestión de documentos electrónicos. Buenos Aires: Alfagrama, 2008.

CONWAY, P. Preservação no universo digital. 2. ed. Rio de Janeiro: Arquivo Nacional, 2001.

CORRÊA, A. M. G. Preservação digital: autenticidade e integridade de documentos em bibliotecas digitais de teses e dissertações. 2010. $96 \mathrm{f}$. Dissertação (Mestrado em Ciência da Informação) - Universidade de São Paulo, São Paulo, 2010. Disponível em: <http://www.teses.usp.br/teses/disponiveis/27/27151/tde-05112010105831/pt-br.php>. Acesso em: 3 jul. 2014.

DE SORDI, J. O. Administração da informação: fundamentos e práticas para uma nova gestão do conhecimento. São Paulo: Saraiva, 2008.

DORNELES, S. L.; CORRÊA, R. F. Gestão de documentos digitais em aplicações de certificação digital. Informação Arquivística, Rio de Janeiro, 
v. 2, n. 2, p. 3-31, jul./dez. 2013. Disponível em: <http://www.aaerj.org.br/ojs/index.php/informacaoarquivistica/article/vie w/28 >. Acesso em: 15 jan. 2015.

FERREIRA, M. Introdução à preservação digital: conceitos, estratégias e atuais consensos, Portugal: Escola de Engenharia da Universidade do Minho, 2006. Disponível em: <https://repositorium.sdum.uminho.pt/bitstream/1822/5820/1/livro.pdf> . Acesso em: 2 ago. 2014.

FLORES, D.; SANTOS, H. M. dos. Preservação de documentos arquivísticos digitais: reflexões sobre as estratégias de encapsulamento. Liinc em Revista, Rio de Janeiro, v. 11, n. 1, p. 167-180, maio/2015. Disponível em: <http://revista.ibict.br/liinc/index.php/liinc/article/view/770>. Acesso em: 2 jul. 2015.

FONSECA, M. O. K. Arquivologia e Ciência da informação. Rio de Janeiro: FGV, 2005.

GIL, A. C. Como elaborar projetos de pesquisa. 4. ed. São Paulo: Atlas, 2010.

HEDSTROM, M. Digital preservation: a time bomb for digital libraries. Computer and the humanities, Netherlands, n. 31, p. 189-202, 1998. Disponível em: < http://deepblue.lib.umich.edu/bitstream/2027.42/42573/1/10579 2004 Article 153071.pdf>. Acesso em: 1 out. 2014.

HEDSTROM, M. Digital Preservation: problems and prospects. USA: University of Michigan, 2001. Disponível em: $<$ http://www.dl.slis.tsukuba.ac.jp/DLjournal/No 20/1-hedstrom/1hedstrom.html >. Acesso em: 10 jan. 2015.

INNARELLI, H. C. Instrumenta 2: preservação de documentos digitais. São Paulo: ARQ-SP, 2012.

INNARELLI, H. C. Preservação de documentos digitais: confiabilidade de mídias CD-ROM e CD-R. 2006. 174f. Dissertação (Mestrado em Engenharia Mecânica) - Faculdade de Engenharia Mecânica, Universidade Estadual de Campinas, Campinas, 2006. Disponível em: $<$ http://www.bibliotecadigital.unicamp.br/document/?code =vtls00038447 9). Acesso em: 6 jun. 2014.

INNARELLI, H. C. Preservação digital e seus dez mandamentos. In: SANTOS, V. B. (Org.). Arquivística: temas contemporâneos, classificação, preservação digital, gestão do conhecimento. Distrito Federal: SENAC, 2007. p. 21-75.

INTERPARES 2 PROJECT. Diretrizes do preservador. A preservação de documentos arquivísticos digitais: diretrizes para organizações. TEAM Brasil. Tradução: Arquivo Nacional e Câmara dos Deputados. 20022007a. 
$<$ http://www.interpares.org/display file.cfm?doc=ip2 preserver guideline s booklet--portuguese.pdf $>$. Acesso em: 9 ago. 2014.

INTERPARES 2 PROJECT. Diretrizes do produtor. A elaboração e a manutenção de materiais digitais: diretrizes para indivíduos. TEAM Brasil. Tradução: Arquivo Nacional e Câmara dos Deputados. 2002-2007b. Disponível em: $<$ http://www.interpares.org/ip2/display file.cfm?doc=ip2 creator guideli nes booklet--portuguese.pdf>. Acesso em: 9 ago. 2014.

LOPES, L. C. A gestão da informação: as organizações, os arquivos e a informação aplicada. Rio de Janeiro: Arquivo Público do Estado do Rio de Janeiro, 1997.

LOPES, L. C. A informação e os arquivos: teorias e práticas. Niterói: EDUFF, 1996.

LUNA, S. V. de. Planejamento de pesquisa: uma introdução. São Paulo: EDUC, 1997.

MARCONDES, C. H. Linguagem e documento: fundamentos evolutivos e culturais da Ciência da Informação. Perspectivas em Ciência da Informação, Belo Horizonte, v. 15, n. 2, p 2-21, maio./ago. 2010. Disponível em: <http://portaldeperiodicos.eci.ufmg.br/index.php/pci/article/view/1019>. Acesso em: 10 fev. 2015.

MÁRDERO ARELLANO, M. Á. Critérios para a preservação digital da informação científica. 2008. 354f. Tese (Doutorado em Ciência da Informação) - Universidade Federal de Brasília, Departamento de Ciência da Informação, 2008.2 Disponível $<$ http://bdtd.bce.unb.br/tedesimplificado/tde busca/arquivo.php?codArqu ivo=4547>. Acesso em: 15 jun. 2014.

MÁRDERO ARELLANO, M. Á. Preservação de documentos digitais. Ciência da Informação, Brasília, v. 33, n. 2, p. 15-27, maio/ago. 2004. Disponível em: $\quad<$ http://revista.ibict.br/ciinf/index.php/ciinf/article/view/305>. Acesso em: 25 jul. 2014.

PAES, M. L. Arquivo: teoria e prática. 3. ed. rev. ampl. Rio de Janeiro: FGV, 2004.

ROCHA, C. L.; SILVA, M. da. Padrões para garantir a preservação e o acesso aos documentos digitais. Acervo, Rio de Janeiro, v. 20, n. 1-2, p. 113-124, jan/dez 2007. Disponível em: $<$ http://www.revistaacervo.an.gov.br/seer/index.php/info/article/view/14 2>. Acesso em: 7 set. 2014.

RONDINELLI, R. C. Gerenciamento arquivístico de documentos eletrônicos: uma abordagem teórica da diplomática arquivística contemporânea. 4. ed. Rio de Janeiro: FGV, 2005. 
RONDINELLI, R. C. O documento arquivístico ante a realidade digital: uma revisão conceitual necessária. Rio de Janeiro: FGV, 2013.

ROTHENBERG, J. Avoiding technological quicksand: finding a viable technical foundation for digital preservation. Commission on Preservation and Access and Council on Library and Information Resources: a report to the Council on Library and Information Resources. EUA: Washington, DC: [s.n.], 1999.

Disponível

em: <http://www.clir.org/pubs/reports/rothenberg/pub77.pdf>. Acesso em: 24 set. 2014.

SANTOS, V. B. dos. Preservação de documentos arquivísticos digitais. Ciência da Informação, Brasília, DF, v. 41 n. 1, p.114-126, jan./abr. 2012. Disponível em: <http://revista.ibict.br/index.php/ciinf/article/view/2110>. Acesso em: 20 dez. 2014.

SANTOS, H. M. dos; FLORES, D. As vulnerabilidades dos documentos digitais: Obsolescência tecnológica e ausência de políticas e práticas de preservação digital. Biblios: Revista de Bibliotecología y Ciencias de la Información, Lima, n. 59, p. 45-54, 2015a. Disponível em: $<$ http://biblios.pitt.edu/ojs/index.php/biblios/article/view/215 >. Acesso em: 4 jul. 2015.

SANTOS, H. M. dos; FLORES, D. Preservação de documentos arquivísticos digitais: reflexões sobre as estratégias de emulação. Encontros Bibli: $R$. Eletr. Bibliotecon. Ci. Inf., v. 20, n. 43, p. 3-19, mai./ago. 2015b. Disponível

$<$ https://periodicos.ufsc.br/index.php/eb/article/view/1518-

2924.2015v20n43p3>. Acesso em: 6 set. 2015.

SANTOS, H. M. dos; FLORES, D. Repositórios digitais confiáveis para documentos arquivísticos: ponderações sobre a preservação em longo prazo. Perspectivas em Ciência da Informação, Belo Horizonte, v. 20, n. 2, p. 198-218, abr./jun. 2015c. Disponível em: < http://portaldeperiodicos.eci.ufmg.br/index.php/pci/article/view/2341>. Acesso em: 3 jul. 2015.

SARAMAGO, M. de L. Metadados para preservação digital e aplicação do modelo OAIS. In: CONGRESSO NACIONAL DE BIBLIOTECARIOS, ARQUIVISTAS E DOCUMENTALISTAS, 8., 2004, Estoril. Anais eletrônicos... Disponível em: $<$ http://www.bad.pt/publicacoes/index.php/congressosbad/article/view/6 40>. Acesso em: 4 jul. 2014.

SAYÃO, L. F. Repositórios digitais confiáveis para a preservação de periódicos eletrônicos científicos. Ponto de Acesso, Salvador, v. 4, n. 3, p. 68-94, dez. 2010a. Disponível em: <http://www.portalseer.ufba.br/index.php/revistaici/article/view/4709>. Acesso em: 8 ago. 2014.

SAYÃO, L. F. Uma outra face dos metadados: informações para a gestão da preservação digital. Encontros Bibli: R. Eletr. Bibliotecon. Ci. Inf., 
Florianópolis, v. 15, n. 30, p.1-31, 2010b. Disponível em: $<$ https://periodicos.ufsc.br/index.php/eb/article/view/1518-

2924.2010v15n30p1>. Acesso em: 10 fev. 2015.

SAYÃO, L. F.; SALES, L. F. Curadoria digital: um novo patamar para preservação de dados digitais de pesquisa. Informação \& Sociedade: Estudos, João Pessoa, v. 22, n. 3, p. 179-191, set./dez. 2012. Disponível em: <http://www.ies.ufpb.br/ojs2/index.php/ies/article/view/12224>. Acesso em: 22 mar. 2015.

SILVA, E. L. da; MENEZES, E. M. Metodologia da pesquisa e elaboração de dissertação. 4. ed. rev. atual. Florianópolis: UFSC, 2005. Disponível em: <https://projetos.inf.ufsc.br/arquivos/Metodologia de pesquisa_e elabor acao de teses e dissertacoes 4ed.pdf>. Acesso em: 13 jun. 2014.

SOMASUNDARAM, G.; SHRIVASTAVA, A. Armazenamento e gerenciamento de informações: como armazenar, gerenciar e proteger informações digitais. Porto Alegre: Bookman, 2011.

THOMAZ, K. de P. A preservação de documentos eletrônicos de caráter arquivístico: novos desafios, velhos problemas. 2004. 389f. Tese (Doutorado em Ciência da Informação) - Escola de Ciência da Informação, Universidade Federal de Minas Gerais, 2004. Disponível em: $<$ http://www.bibliotecadigital.ufmg.br/dspace/bitstream/handle/1843/VAL A-68ZRKF/doutorado katia_de_padua thomaz.pdf $>$. Acesso em: 28 jul. 2014.

THOMAZ, K. de P. Documentos eletrônicos de caráter arquivístico: fatores condicionantes da preservação. Perspectivas em Ciência da Informação, Belo Horizonte, v. 10 n. 1, p. 34-53, jan./jun. 2005. Disponível em: <http://portaldeperiodicos.eci.ufmg.br/index.php/pci/article/view/301>. Acesso em: 7 set. 2014.

THOMAZ, K. de P.; SANTOS, V. M. dos. Metadados para o gerenciamento eletrônico de documentos de caráter arquivístico - GED/A: estudo comparativo de modelos e formulação de uma proposta preliminar. DataGramaZero, Rio de Janeiro, v. 4, n. 4, ago./2003. Disponível em: <www.dgz.org.br/ago03/Art 04.htm>. Acesso em: 1 set. 2014.

THOMAZ, K. de P.; SOARES, A. J. A preservação digital e o modelo de referência Open Archival Information System (OAIS). DataGramaZero, Rio de Janeiro, v. 5 n. 1, fev. 2004. Disponível em: <www.dgz.org.br/fev04/Art 01.htm>. Acesso em: 10 jun. 2014.

WEBB, C. Guidelines for the preservation of digital heritage. Preparado pela Biblioteca Nacional da Austrália para a Divisão de Sociedade de Informação, UNESCO, relatório n. CI-2003/WS/3. 2003. Disponível em: $<$ http://unesdoc.unesco.org/images/0013/001300/130071e.pdf > .

Acesso: em 17 Ago. 2014. 